\title{
A floresta e os produtos químicos naturais
}

\author{
Roberto Figliuolo*
}

O rápido progresso das ciências física e química e da tecnologia neste século, e o vertiginoso crescimento da população humana em todas as partes do globo, têm conduzido a profundas alterações nas paisagens naturais. Essas modificações resultam dos objetivos tradicionais, estritamente econômicos que têm orientado o homem na exploração dos recursos naturais, renováveis ou não.

Cientistas naturais, culturalmente ecléticos, têm, nas últimas décadas, podido juntar uma série de comprovações a cerca dos males colaterais que esse mesmo processo vem causando ao próprio homem. Constitui-se em um dever individual alertar os administradores e políticos de todas as nações e, principalmente, aos do Brasil, com especial ênfase aos da Amazônia, acerca dos graves errcs em que incorremos contra a economia nacional e a humanidade se insistirmos em explorar os recursos naturais, ignorando ou omitindo as Ieis que regem os processos naturais sobre os quais se assenta o equilíbrio ecológico.

Se a exploração da Amazônia se fizer nos moldes tradicionais (ou seja nos moldes consagrados pela civilização industrial, baseada na expansão contínua do processo industrial, deferidido por Economistas e Engenheiros, sem levar-se em conta a necessidade de manter-se o equilíbrio ecológico dinâmico), a biocenose amazônica se converterá, após a derrubada de sua floresta, em um "deserto" (Nimer, 1975).

A União Internacional para a Conservação da Natureza considera a conservação como "o manejo dos recursos do ambiente com o propósito de obter qualidade sustentável de vida humana". O dogma do crescimento ilimitado e a quaiquer preço, que rege a atual sociedade industrial, deve dar lugar à doutrina do equilíbrio e da qualidade de vida. Progresso não mais se mede, de acordo com o atual estágio da consciência sócio-científica humana, com índice tão simplório, insensível e desconcer-
Cancie quanto o PivB. Progresso é, então, algo muito mais complicado, inclui, predominantemente, fatores que nada têm a ver com fluxo de dinheiro e movimentação de materiais, tais como a maior disseminação da felicidade individual melhor integração do homem em seu ambiente; mais estável e mais harmônica estrutura social, mais cultura, mais excelência intelectual, mais arte, intercâmbio social, mais alegria de vida. A ênfase está tơda na qualidade, não na quantidade. O que interessa é a manutenção do patrimônio real, material e espiritual, não o simples incremento do capital monetário (Lutzenberger, 1977).

\section{O POTENCIAL BIÓTICO DA FLORESTA AMAZÔNICA NA PROTEÇÃO DE CULTURAS VEGETAIS}

Para fornecer alimentos a toda a população atual, num padrão de vida considerado pelas Nações Unidas apenas como mínimo condizente com a espécie humana, seria necessário aumentar a produção mundial nas seguintes proporções: cereais $50 \%$, carnes $90 \%$, leite e derivados $125 \%$, óleos vegetais $125 \%$, frutos e legumes $300 \%$. Este é o fato dramático e mais importante com que o homem hoje se defronta, pois como será possível a vida daqui a 25 anos se tivermos um efetivo de 6 bilhões, por conseguinte muito maior que dos nossos dias? (Guerra, 1976).

Apesar de todos os meios disponíveis para a proteção de culturas vegetais, cerca de $1 / 3$ da safra anual do mundo (equivalente a 75 biIhões de dólares) é destruída por pragas. Os países tropicais, por causa da temperatura e particularidades do meio ambiente, sofrem as mais drásticas conseqüências face a esse mal.

Durante os últimos trinta anos, pesquisas básicas em biologia e bioquímica de plantas e insetơs têm tornado possível divisar não somente novos pesticidas mas também um método completamente novo para a proteção de plantas, usando produtos do metabolismo 
secundário vegetal, os quais podem ser tóxicos a espécies específicas de pragas e completamente inofensivas ao homem.

Pesquisas em bioquímica a fisiologia de insetos têm levado à descoberta não somente de hormônios mas também a outras substâncias (repelentes, atraentes, anti-alimentares e feromônios) as quais condicionam o comportamento dos insetos. Por exemplo, mais de 400 substâncias repelentes têm sido isoladas e caracterizadas de 700 espécies de artrópodos, e tem-se informações estruturais de substâncias que afetam a físiologia ou o comportamento de um certo número de insetos. Algumas substâncias como as ecdisonas não são disponiveis em grande quantidade, porém novas importantes fontes desses hormônios têm sido encontradas em plantas.

A maioria destes tipos de substâncias possui estrutura molecular simples, tornando viável suas sinteses $e$ de análogos para ensaios biológicos.

Recentemente, uma descoberta de particular importância foi a presença de precocenos em plantas. Estas substâncias de estruturas simples pertencendo ao grupo dos cromenos, modificam a função dos hormônios juvenis e sob sua influência são produzidas insetos anões. O uso de precocenos abre novos horizontes no controle químico de insetos (Marini-Bettòlo, 1977) .

A bioquímica de plantas resistentes é uma outra via de acesso para a proteção de culturas vegetais contra ataques de insetos ou fungos. A resistência é devida a presença de substâncias as quais são acumuladas em todas as linhagens resistentes. Muitas dessas substâncias têm sido isoladas e suas estruturas determinadas. São denominadas fitoalexinas. Neste particular, a floresta amazônica deve ser extremamente rica de exemplos, pois não há árvore que não sofra ataque por fungos e insetos. Ressalte-se, no entanto, que por uma via tão sutil de controle, que nem hóspede nem parasita são afetados de um modo tal que venha a interromper a contituidade funcional de cada um dentro do ecossistema.

\section{O POTENCIAL MADEIREIRO}

O recurso florestal de maior interesse na Amazônia é o imenso potencial madeireiro, estimado em 50 bilhões de metros cúbicos de madeira em pé. Esse maior interesse no potencial madeireiro da Amazônia é fácil e obviamente entendido em virtude de :

- a Hiléia amazônica, constitui, atualmente, a última grande reserva de madeiras tropicais do mundo e, por isso, sobressai como a grande reserva que, nos próximos decênios, deverá abastecer a demanda mundial;

- a evolução do mercado madeireiro internacional evidencia que as importações quadruplicaram nos últimos 20 anos, e que, no final do século, o nivel atingirá a 400 milhões de metros cúbicos. As necessidades mundiais de madeira, portanto, crescem em rítmo geometricamente acelerado;

- está próximo o esgotamento das reservas nos países tradicionalmente abastecedores de madeiras tropicais, isto é, de auto-suficientes se tornarão, em escala cada vez maior, importadores. Pode antever-se então, que as madeiras da Amazônia alcançarão penetração crescente no Mercado Internacional;

- a demanda futura de madeira no Brasil deverá crescer consideravelmente, já que as florestas naturais das demais regiões brasileiras, estão praticamente, extintas, sendo difícil e remota a possibilidade de suprimento das necessidades crescentes do País, através dos projetos de reflorestamento em execução.

Tudo isso leva à conclusão de que a grande Hiléia não pode permanecer como simples ornamento da palsagem regional, nem tão pouco deverá continuar a ser considerada como mera ocupante transitória do terreno ou ser alvo das práticas predatórias atualmente usadas (Pandolfo, 1978).

É preciso, no entanto, ficar-se alerta aos interesses empresariais imediatistas e gananciosos, que se sobrepõem aos superiores interesses sociais e econômicos de desenvolvimento e de preservação ecológica da região. Exatamente em virtude desses interesses é que hoje a Amazônia se constitui na última grande reserva florestal do mundo; acabaramse todas as outras por onde, inadvertidamente, se deixou penetrar as devastadoras garras de empresários ávidos pelas riquezas, disseminando agressões drásticas ao meio ambiente, agravando até as condições de habitabilidade e de bem estar das comunidades usurpadas. 
Eles agora estão sedentos por novos lucros; a cata de novos tesouros para tornarem irreversivelmente dilapidados.

E preciso, também, que se atente para ou tras atividades florestais que podem levar a lucros mais vultosos e menos predatórios que os tradicionalmente empregados pela indústria madeireira.

\section{POTENCIAL BIOLÓGICO, FARMACOLÓGICO E TERAPÊUTICO}

O homem tem tirado vantagens daquilo que supomos tratar-se de substâncias de defesa das plantas, para o combate de suas doenças e, exatamente, estas substâncias é que constituem, hoje, a grande maioria de todas as formulações farmacêuticas cornerciais encontradas no mundo.

É realmente providencial que a Amazônia tenha podido conservar o seu valiosíssimo potencial vegetal natural até os dias atuais, quando a carência mundial de matéria-prima, proveniente desse recurso, lhe permitirá ingressar no ciclo da produção florestal com uma situação de mercado altamente favorável. Desejase, no entanto, que seja de uma maneira inteligente e racional para que não se decrete igual destino de outras florestas naturais outrora existentes na Terra.

Apresenta-se a floresta amazônica, sob o ponto de vista de flora que ostenta e da fauna que a habita, como um vasto repositório, verdadeiramente surpreendente, de espécies de valor econômico, essenciais às necessidades da vida moderna, algumas já conhecidas nos mercados, como é o caso da seringueira, da castanha-do-Pará, das oleoginosas diversas, além de uma imensa gama de essências laticíferas, têxteis, tintoriais, taniferas aromáticas, medicinais e de usos industriais os mais diversos (Pandolfo, 1978).

É com grande probabilidade que espécies amazônicas via de regra, completamente desconhecidas, no que concerne ao conteúdo de seus interstícios, possa fornecer outros produtos de maior necessidade para a humanidade do que simplesmerite a madeira, a qual é usada, na maioria das vezes, como matéria fisica para a produção de bens de consumo supérfluos.
Não se tem dúvida de que os organismos vivos nos trópicos enfrentam uma competição mais rigorosa do que os que vivem em zonas temperadas. Não será nenhuma surpresa, portanto, encontrar-se uma rica variedade de substâncias e mecanismos de defesa nos organismos tropicais. Elaborados mecanismos de defesa imunológica, no caso dos mamiíieros, desempenham, fundamentalmente, a proteção dos indivíduos contra a invasão de microorganismos, patogênicos, mas com plantas. fungos e animais invertebrados, a defesa química deve desempenhar a mais importante função de proteção. É uma pena que tão pouco, ou quase nenhum trabaiho cuidadoso tenha sido feito para eluciciar estas funçōes nas plantas tropicais, no Brasil, e em particular, na Amazônia, onde habita a maior e a mais diversificada floresta da terra. (Gilbert, 1977).

Somente conhecemos alguns dos constituintes de 470 plantas das 120.000 espécies nativas brasileiras. Conclusão: em relação ao número de espécies não conhecemos nada sobre a química de $99,6 \%$ da flora brasileira [Gottlieb \& Mors, 1979].

Evidenciando toda a imensa potencialidade biológica, farmacológica e farmacêutica-industrial da flora brasileira lé impossível fazer-se um breve resumo de todas as substâncias $e$ atividades sem, no mínimo, tornar este artigo longo e excessivamente técnico) Gottlieb \& Mors (1979) relacionam, em ciagramas, o conhecimento químico que tem sido adquirido sobre os constituintes de plantas brasileiras, em grande parte amazônicas, proporcionando: 1 - não somente um ou dois exemplos, mas um grupo de substâncias biogeneticamente re. iacionadas que têm sido isoladas; 2 - atividade bio-dinâmica, relativa no mínimo a urn de seus membros.

"Uma folha pode ter 50 constituintes diversos. A descoberta de deles pode ser mais importantes para a humanidade que a descoberta de uma galáxia". É fácil concordar com este dictum de Sir Robert Robinson, laureado com o Prêmio Nobel, pois: 1 - a energia armazenada nestas substâncias é essencial a toda vida animal, e nada impede, do ponto de vista teórico, que um dia seja usada em escala igualmente geral para fins técnicos; 2 - as propriedades biológicas destas substâncias 
são essenciais ao desenvolvimento do própric vegetal e ao controle que exerce sobre a vida que o rodeia, não sendo de admirar, por isto, que tenham sido aproveitadas pelo homem seja diretamente, seja como modelo de síntese de fármacos (Gcmes \& Gottlieb, 1977).

\section{O VALOR BIOLÓGICO E COMERCIAL} DE DROGAS OBTIDAS DE PLANTAS

O povo americano, em 1973, pagou cerca de 3 bilhões de dólares por drogas que são extraídas de plantas superiores. De 1.532 bilhão de prescrições aviadas em 1973, 25,2\% (Quadro 1), continham um ou mais constituintes ativos obtidos de plantas superiores (Farnsworth \& Bingel, 1977).

QUADRO 1 - Comparação das origens dos produtos naturais contidos nas prescrições aviadas em 1959 e 1973 (Farnswerth \& Bingel, 1977).

\begin{tabular}{lcccc}
\hline Ano & $\begin{array}{c}\text { Plantas } \\
\text { Superiores }\end{array}$ & Micróbios & Animaís & Total \\
\hline 1959 & $25,5 \%$ & $21,4 \%$ & $2,3 \%$ & $49,2 \%$ \\
1973 & $25,2 \%$ & $13,3 \%$ & $2,7 \%$ & $41,2 \%$ \\
\hline
\end{tabular}

Embora o número total de prescrições tenha aumentado dramaticamente no período entre 1959 e 1973, a percentagem de prescrições de produtos naturais permaneceu algo constante (Quadro I) indicando dois principais pontos :

1. que produtos naturais representam um mercado extremamente estável nos Estados Unidos, e;

2. que, por causa desta estabilidade, pode ser seguramente assumido que as drogas representadas neste levantamento são de inteira confiança dos médicos.

Um total de 76 diferentes compostos químicos de estruturas conhecidas e 99 diferentes tipos de extratos brutos, ambos derivados de plantas superiores, foram usados nas prescrições analisadas em 1973. Das 76 drogas. somente 7 são comercialmente produzidas por sintese : emetina, cafeína, teobromina, teofilina, pseudoefedrina, efedrina e papaverina.
Todos os dados supracitados, ainda que, sejam restritos aos Estados Unidos, permitem supor que drogas derivadas de plantas superiores são, no mínimo, de igual importância em outros países do mundo.

Um total de 2.399 compostos naturais com estruturas inéditas e 3.965 compostos naturais com estruturas conhecidas foram isolados no ano de 1975. (Quadro 2)

QUADRO 2 - Número de compostos naturais isolados em 1975, por classes de organismos (Farnsworth \& Bingel, 1977).

\begin{tabular}{lrr}
\hline \multicolumn{1}{c}{ Grupo Vegetal } & $\begin{array}{c}\text { Estrutura } \\
\text { Inédita }\end{array}$ & $\begin{array}{c}\text { Estrutura } \\
\text { Conhecída }\end{array}$ \\
\hline Monocotiledôneas & 97 & 277 \\
Dicotiledôneas & 1.504 & 2.579 \\
Gimnospermas & 49 & 221 \\
Pteridófitas & 29 & 90 \\
Briófitas & 17 & 32 \\
Líquens & 14 & 44 \\
Fungos e Bactérias & 479 & 523 \\
Organismos Marinhos & 210 & 199 \\
& & \\
\hline
\end{tabular}

Demonstrando o valor comercial destes compostos, mais de 400 patentes foram requeridas somente para substâncias isoladas de plantas superiores em 1975 . Neste mesmo ano, foram publicadas cerca de 1.000 sínteses de produtos naturais e as estruturas de 275 produtos naturais foram determinadas por análise em Raio-X.

Um total de 325 compostos, isolados somente de plantas superiores, constam da literatura de 1975 como tendo um ou mais tipos de atividade biológica em algum sistema, revelando suas potenciabilidades como drogas. Dos 325 compostos, 93 eram de estruturas inéditas, e 232 com estruturas conhecidas (Quadro 3). Estes dados não incluem um grande número de casos em que interessante atividade biológica de extratos de organismos que ainda permanecem em estudos para isolamento de seu (s) princípio (s) ativo (s).

As várias categorias de atividade biológica para os 325 compostos que constam da literatura em 1975, apresentando um ou mais tipo de atividade biológica figuram no Quadro 4 . 
QUADRO 3 - Classes de produtos vegetais possuindo atividade biológica, reportados na literáiura de 1975 (Farnsworth \& Bingel, 1977) (').

\begin{tabular}{|c|c|c|c|c|c|c|c|c|}
\hline $\begin{array}{l}\text { Classe de } \\
\text { Compostos }\end{array}$ & $\begin{array}{l}\text { Inédi- } \\
\text { tos (2) }\end{array}$ & $\begin{array}{l}\text { Conhe- } \\
\text { cidos (3) }\end{array}$ & $\begin{array}{l}\text { Classe de } \\
\text { Compostos }\end{array}$ & $\begin{array}{l}\text { Inédi- } \\
\text { tos (2) }\end{array}$ & $\begin{array}{l}\text { Conhe- } \\
\text { cidos (3) }\end{array}$ & $\begin{array}{l}\text { Classe de } \\
\text { Compostos }\end{array}$ & $\begin{array}{l}\text { Inédi- } \\
\text { tos (2) }\end{array}$ & $\begin{array}{l}\text { Conhe- } \\
\text { cidos (3) }\end{array}$ \\
\hline Alcalóides & 24 & 49 & Monoterpenos & 1 & 12 & Tiofenos & 0 & 2 \\
\hline Sesquiterpenos & 19 & 28 & Simarubolides & 8 & 1 & Sulfetos & 0 & 2 \\
\hline Diterpenos & 12 & 14 & Ácidos Fenó- & & & Nitroderivados & 0 & 2 \\
\hline $\begin{array}{l}\text { Saponinas } \\
\text { triterpenoidais }\end{array}$ & 2 & 20 & $\begin{array}{l}\text { licos } \\
\text { Aminoácidos }\end{array}$ & $\begin{array}{l}2 \\
0\end{array}$ & $\begin{array}{l}6 \\
8\end{array}$ & $\begin{array}{l}\text { Fenilpropa } \\
\text { nóides }\end{array}$ & 0 & 2 \\
\hline Triterpenos & 5 & 13 & Lignanas & 2 & 4 & Saponinas es- & & \\
\hline Flavonóides & 2 & 16 & Carbocíclicos & 0 & 5 & teroidais & 0 & 2 \\
\hline Cumarinas & 1 & 14 & Benzenóides & 2 & 2 & Cardenolides & 0 & 2 \\
\hline Quinonas & 4 & 11 & Ésteres e Áci- & & & Cianoderivados & 1 & 0 \\
\hline Esteróides & 7 & 10 & dos Graxos & 1 & 3 & Naftalenos & 0 & 1 \\
\hline & & & Isotiocianatos & 0 & 2 & Xantonas & 0 & 1 \\
\hline
\end{tabular}

(1) o número totol é 325 ;

(2) O número total é 93;

(3) O número total é 232 .

QUADRO 4 - Número de produtos vegetais biologicamente interessantes por categoria de atividade. reportados na literatura de 1975 (Farnsworth \& Bingel, 1977).

\begin{tabular}{|c|c|c|c|c|c|}
\hline $\begin{array}{l}\text { Tipo de atividade } \\
\text { biológica }\end{array}$ & Número & $\begin{array}{c}\text { Tipo de atividade } \\
\text { biológica }\end{array}$ & Número & $\begin{array}{c}\text { Tipo de atividade } \\
\text { biológica }\end{array}$ & Número \\
\hline Analgésico & 8 & Catártico & 1 & Hipotensivo & 8 \\
\hline Anoréxico & 2 & Antihelmíntico & 5 & Imunossupressor & 1 \\
\hline Antiarrítmico & 2 & Antibacterial & 30 & Inseticida & 2 \\
\hline Antiazotêmico & 1 & Antifúngico & 28 & Repelente de Insetos & 1 \\
\hline Anticonvulsante & 3 & Antimicoplásmico & 2 & Antipsoriasis & 1 \\
\hline Antiemético & 1 & Antiprotozoário & 30 & Espamolítico & 7 \\
\hline Antifertilizante & 4 & Antiviral & 3 & Espermicida & 3 \\
\hline Antihepatotóxico & 3 & Colerético & 5 & Teratógeno & 6 \\
\hline Antihistaminico & 4 & Colinomimético & 1 & Inibidor de Tumor & 63 \\
\hline Antinflamatório & 32 & Agente ativo ao SNC & 14 & Cíotóxicc & 49 \\
\hline Antivômito & 4 & Vasodilatodor Coronário & 1 & Promotor de Tumor & 25 \\
\hline Antitússico & 3 & Diurético & 4 & Estimuiante Uterínico & 1 \\
\hline Anticâncer & 12 & Veneno de Peixe & 1 & Vasodilatador & 1 \\
\hline Antihemorrágico capilar & 2 & Gona otróf:co & 1 & Diversos & 3 \\
\hline Cardiotônico & 1 & Hipocoiesterolêmico & 22 & & \\
\hline Cardiovascular & 5 & Hipsol c smico & 13 & & \\
\hline
\end{tabular}


É significativo apontar que menos de $5 \%$ das estruturas inéditas isoladas de plantas superiores, em 1975, foram avaliadas para qualquer tipo de atividade biológica.

Virtualmente, toda classe farmacológica de drogas inclui um produto natural (muitos deles derivados de plantas superiores) como protótipo, que exibe o efeito clássico da categoria farmacológica em questão e, portanto, desempenham um importante papel na pesquisa de estudos farmacológicos.

limportante desígnio na descoberta em plantas de novas estruturas com atividade biológica é proporcionar modelos para a síntese de análogos $\mathrm{e} / \mathrm{ou}$ derivados com equivalente ou melhor atividade. Para citar um exemplo, a cocaína forneceu informações aos químicos, que conduziram à produção de anestésicos locais relacionados, tais como a procaína e seus congêneres. Não há dúvida, nơ entanto, de que produtos naturais, freqüentemente, possuem muito mais sutis afinidades de estrutura-atividade que os produtos sintéticos usados na medicina e na agricultura.

O valor de compostos químicos derivados de plantas superiores como ponto de partida para derivados semi-sintéticos não pode ser subestimado. O exemplo clássico é o uso da diosgenina como matéria-prima para a síntese da maioria dos hormôniớs estereoidais comu. mente usados na medicina.

Outras aplicações úteis de produtos naturais derivados de plantas superiores podem ser citadas; por exemplo, bixina como corante para alimentos; ácido nor-dihidroguaiarético ccmo anti-oxidante de gorduras; óleos essenciais e seus derivados terpênicos como perfumes e agentes flavorizantes; etc.

Seja qual for a aplicação prática de produtos naturais derivados de plantas superiores seguem-se os evidentes reflexos no setor agrícola da produção por induzir a uma exploração racional de plantas cultivadas ou silvestres.

\section{CONCLUSÕES}

Entre todas as dificuldades inerentes ao processo de buscas de novas drogas derivadas de plantas, o mais importante dissuasor de tal pesquisa, no mundo inteiro e principalmente no Brasil, é a indiferença por parte de Funda- ções, Universidades, Institutos de Pesquisás e Indústrias em proporcionar adequados recursos financeiros por tempo suficiente para que um plano, com essa finalidade, possa produzir agentes clinicamente úteis.

Seja permitido lembrar a estas entidades que muitcs produtos de plantas brasileiras tiveram sua utilidade e empregos demonstrados, patenteados e utilizados por empreendimentos estrangeiros. Não resta dúvida que o interesse pela morfologia, pela química e pela farmacologia de plantas brasileiras é maior na Suiça, na Alemanha, na França, na Itália e nos Estados Unidos do que aqui (Gomes \& Gottlieb, 1977).

Além disso, no Brasil, não existem esforços conjugados entre os químicos especializados em produtos naturais e farmacólogos, no sentido de desenvolver planos de pesquisas prioritários em setores de maiores perspectivas de êxitos, não só econômicơs mas também científicos. O que existe, no entanto, são estímulos voltados para a competição, fragmentando recursos financeiros e repelindo cooperações técnicas e comunhão ds idéias que, se existissem, certamente, conduziriam grupos à vanguarda científica e ievariam ao povo os benefícios naturais decorrentes.

Enquanto essa situação caótica existe, a média de derrubada diária no Brasil é de 1 milhão e meio de árvores. Na Amazônia, nos últimos dez anos derrubaram-se mais árvores do que no decorrer dos três séculos anteriores. E o pior é que, embora se exporte alguma madeira da Amazônia, destrói-se mais em sua coleta, isto é, a margem de desperdício supera a margem de aproveitamento. Embora com índice demográfico baixo, a população da Amazônia atual é excessiva, por, somente se manter às custas da destruição irreversível de seus recursos ou pela importação de recursơs alheios.

Mais que as reservas de combustivel e minerais estratégicos, hoje em dia acredita-se que as reservas de alimentos deverão aumentar a força de barganha das grandes potências no conceito internacional. Apesar dos fracassos a que estão destinados os atuais empreendimentos agropecuários na Amazônia, pois se precisa de mais pesquisas para definir o tipo de manejo mais adequado para o 
estabelecimento de suas práticas, a região amazônica é, por vocação, produtora de alimentos. Assim, não precisamos adaptá-la aos conceitos que temos tradicionalmente sobre como devem ser produzidos alimentos. O potencial nutritivo da Amazônia, desde que natural, não deve, por certo vir de tradicionais manejos agropecuários, que antes de tudo contribui para a destruição do meio ambiente, mas sim da racionalização da fauna ictiológica como fonte de proteínas para o mundo, através de fazendas aquáticas, naturalmente existentes (Alvim, 1978 a).

Obviamente, ainda necessitamos de muita pesquisa básica na região amazônica antes que possamos propor programas muito ambiciosos para seu desenvolvimento agrícola, pecuário e silvicultural. Até que tenhamos os resultados dessas pesquisas, teremos de contentar-nos em promover tais programas em áreas limitadas, bem selecionadas e principalmente, em escala piloto, a nivel puramente de pesquisa. Os limites de expansão de cada atividade deverão ser controlados por órgãos especializados, ou previamente definidos e, de acordo com os interesses do país. E racional e inteligente recomendarmos agora, isto é, baseado no atual volume de dados cientificamente estabelecidos até o momento, que a maior parte da região amazônica permaneça intocada como reserva para o futuro. O que não devemos é implantar o intruso e o exótico, alterando criminosamente a sua fisionomia. Não devemos usar papel carbono. Temos que criar coisas nossas. Práticas agrícolas para clima tropical e subtropical, sem julgar por padrões de clima temperado. O aproveitamento da Amazônia há de ser racional e científico. Insânia seria a derrubada de nossas florestas naturais heterogêneas construídas naturalmente, a um conhecimento científico que nós ainda não possuímos e temos que pesquisá-lo em vez de substituílas por florestas artificiais homogêneas, de pinheiros, eucaliptos, etc. Isso porque a natureza ficaria profundamente alterada ou desequilibrada, com o desaparecimento da própria fauna (Alvim, 1978 b] .

A irreverência do processo de devastação dos recursos naturais vegetais no Brasil e em especial na Amazônia, é irracional, revoltante e vergonhosa. Somente os argumentos e dados citados relativos ao aproveitamento de substâncias naturais de origem vegetal como drogas, justificariam a preservação desses recursos e o devido estímulo à pesquisa nesse setor. Assim mesmo, isto significa uma pequena parcela do nosso prejuizo total se considerarmos a infinidade de conhecimentos que poderíamos obter, se nos fosse dada a oportunidade de aprender a imitar todos os processos naturais envolvidos nesses inúmeros sistemas destruídos irreversivelmente, que foram elaborados durante bilhões de anos de evolução .

Felizmente, a ciência moderna, no afá de solucionar racionalmente os cruciais problemas que afligem as populações da terra, parece voltar-se mais e mais no sentido de desvendar os processos naturais, a fim de possibilitar a sua aplicação por processos tecnológicos.

Um exemplo nítido de tal tendência são os esforços que vêm sendo dispensados para o aproveitamento da energia solar através da fotossíntese, agora que todas as previsões indicam o esgotamento das reservas petrolíferas mundiais a médio prazo.

Em relação ao problema energético mundial, o Prof. M. Calvin declara: "O que nós cientistas devemos fazer é tomar os conhecimentos adquiridos e idealizar meios sintéticos de obter os mesmos tipos de processos energéticos como todas plantas verdes fazem por sí só, requerendo apenas a luz do sol. A primeira e imediata possibilidade para o desenvolvimento de um sistema economicamente útil para o aproveitamento da energia solar é usar o melhor e o mais antigo esquema que nós conhecemos de captura dessa energia: as plantas verdes. Selecionado e modificando-as produzirão os compostos que nós gostaríamos de obter, os hidrocarbonetos de adequado peso molecular e estrutura" (Calvin, 1978).

E. importante ressaltar que o aproveitamento da energia solar pela sua conversão em energia química e matéria através dos caminhos da redução do carbono e conversão quântica nas plantas verdes, não alťera o equilíbrio térmico do planeta, é relativamente livre de controle político, globalmente possível em 
base renovável, e, portanto inesgotável, e, ambientalmente puro.

A Floresta de Terra Firme da Amazônia brasileira cobrindo cerca de $3.303 .000 \mathrm{~km}^{2}$, é o maior coletor de energia solar da terra. Usando métodos de aproveitamento auto-sustentável com rendimentos progressivamente melhores, atualmente não disponíveis, mas que poderão ser conquistados, mesmo a curto prazo, se pesquisas específicas forem efetuadas, poderia tornar-se em escala global, a maior exportadora de energia da Terra e suprir o mundo com inseticidas naturais, agentes controladores de pestes e uma ampla gama de agentes farmacológicamente ativos. Uma simples e racional indústria extrativa, desse modo auto-sustentável, poderia fornecer imediatamente extratos vegetais brutos biodegradáveis para uso onde os produtos sintéticos já estão causando problemas.

Irracional, revoltante e vergonhosamente, no entanto, a maior floresta do mundo está sendo consumida irreversivelmente. E o pior é que, nós sabemos que aquilo que está sendo destruído vale muito mais do que aquilo que, se vai criar ou cultivar sem a certeza dos resultados.

É hora, pois, de começarmos a usar, principalmente na Amazônia, enquanto*algo ainda existe, os conhecimentos adquiridos através de pesquisas básicas é de combater a excessiva subjetividade e parcialidade na planificação e antecipação do futuro que se deseja.

E preciso enfatizar-se, veementemente, que a pesquisa fundamental ainda que seja considerada por muitas pessoas e mesmc, ou principalmente, por alguns administradores de órgãos financiadores oficiais de pesquisas, como um exercício acadêmico e até mesmo um luxo, somente os resultados de muitos anos de pesquisas fundamentais permitem novas soluções práticas para problemas extremamente difíceis que devem ser resolvidos. Isto, é particularmente legítimo em relação à proteção de culturas vegetais onde as novas soluções devem surgir baseadas nos conhecimentos interdisciplinares das pesquisas fundamentais em biologia, bioquímica, química e fisiologia de plantas e insetos.

\section{BIBLIOGRAFIA}

ALVIM, P.T.

1978a - Ocupação racional da Amazônia brasiieira. Repostas a um questionário sobre a ocupação da Amazônia. Silvicultura, 2(9) : 1722 .

1978b - Floresta Amazônica: equilíbrio entre utılização e conservação. Ciência e Cultura, 30(1) : 9-16.

Calvim, $M$.

1978 - Green Factories. Chemica \& Engineering News, 56(12) : 30-36.

FARNSWORTH, N.R. \& BINGEL, A.S.

1977 - Problems and Prospects of Discovering New Drugs from Higher Plants by Pharmacological Screening. In: New Natural Products and plant drugs with pharmacological, biocologial or thera pentical Activity. Ed. H. Wagner and P. Wolff, Springer, Berlin. p. 1.

GiLberT, B.

1977 - Natural product derivatives in tropical Insect and parasite control. In: Produits naturels et al protection des plantes. Ed. G.B. Marini-Bettolo, Pontificia Academia Scientiarum, Cittá del Vaticano, p. 225.

Gomes, C.M.R. \& GoTtLIEB, O.R.

1977 - Cadastro Fitoquímico Brasileiro. Instituto de Química Universidade de São Paulo. Ed. São Paulo. 84 p.

Gottlieb, O.R. \& Mors, W.B.

1979 - Potencial Utilization of Brazilian Wood Extractives. J. Agric. Food. Chem.: (no prelo).

Guerra, A.T

1976 - Recursos Naturais do Brasil. IBGE, Rio de Janeiro 2." Ed., 217 p.

LUTZENBERGER, J.A.

1977 - Tecnologia, ambiente, sociedade. Alternativa fatal. Associação Gaucha de Proteção ao Ambiente Natural. $18 \mathrm{p}$

Nimer, E.

1975 - A conservação da natureza ante a exploração econômica da Amazônia. Revista Brasileira de Geografia, 2:44-74.

Marini-Bettòlo, G.B.

1977 - Produits Naturels et la Protection des Plantes. Ed. G.B. Marini-Bettolo Pontificia Academia scientiarum Cittá del Vaticano. $846 \mathrm{p}$.

Pandolfo, C.

1978 - A floresta amazônica brasileira - um enfoque econômico - ecológico. Ministério do Interior. SUDAM. 